Br J Gen Pract 2017; DOI: https://doi.org/10.3399/ bjgp17X689017.

DOI: https://doi.org/10.3399/bjgp17X690101

\section{Clinical and cultural conflicts}

As a GP working in the Middle East, I can totally understand Dr Sherifi's concern. ${ }^{1}$ Unfortunately end-of-life care and palliative care medicine are in their infancy. This is because of a lot of cultural and religious factors held by both patients' families and healthcare professionals. In some of the Gulf countries, the do not attempt resuscitation (DNAR) forms and decision were just introduced a few months ago. However, I hear from colleagues in critical care who received complaints from fellow staff members despite family approval, for interfering with God's will or acting like God by withdrawing treatment. I have to say it is a very difficult situation for the doctors working there and they just simply have to abide by the rules of the land. I am sorry that your uncle and family have to go through this distress.

Yusr Jaafir,

Family Medicine Consultant/GP, OPD.

E-mail: yusr79lagmail.com

\section{REFERENCE}

1. Sherifi J. Clinical and cultural conflicts. $\mathrm{Br} J$ Gen Pract 2017; DOI: https://doi.org/10.3399/ bjgp17X689653.

\section{Discharge summary information: more than DVT warnings needed}

My out-of-hours duty shift today echoed this article.' While recognising that usually it should be the family and perhaps the family doctor to get involved proactively, perhaps we should suggest to our colleagues in hospital that it would be far more useful on discharge summaries of the frail and declining group of patients that end-of-life care, choice of place to die, wishes for readmission, and do no attempt resuscitation (DNAR) had all been discussed rather than documenting that they have been warned about DVT.

In my personal view we should also move away from the need to have a DNAR form to allow someone to peacefully die. Putting these responsibilities onto the visiting outof-hours team with no prior knowledge is neither safe or fair.

Nicholas J Sharvill,

GP, Portfolio GP including out of hours. E-mail: john.sharvillanhs.net

\section{REFERENCE}

1. Sherifi J. Clinical and cultural conflicts. $\mathrm{Br} J$ Gen Pract 2017; DOI: https://doi.org/10.3399/ bjgp17X689653.

DOI: https://doi.org/10.3399/bjgp17X690125

\section{The role of general practice in surgical trials}

We read with much interest the editorial by Keshav and Stevens, ${ }^{1}$ which discusses a broad overview of the advancements in the knowledge of iron deficiency anaemia (IDA) with emphasis on management. We encourage GPs and community medicine to engage in the research on the condition, which remains one of the greatest burdens to global health. ${ }^{2}$ Their comments regarding implementation of parenteral iron therapy to manage IDA is of particular importance for a number of reasons.

The awareness of and education currently available to GPs for IDA does not reflect major advances in the aetiology and particularly the unrecognised impact on patient welfare. This has led to considerable under-management of IDA. For example, a large percentage (the average being 30\%) of elective surgical patients, many of whom are pre-emptively referred by GPs, are in fact found to have IDA. ${ }^{3}$ Preoperative anaemia is independently associated with poorer outcomes. ${ }^{4}$ Recognising and managing preoperative anaemia is supported by authoritative bodies such as the Association of Anaesthetists of Great Britain and Ireland (AAGBI), NHS Blood and Transplant (NHSBT), and the National
Institute for Health and Care Excellence (NICE).

However, it is not clear whether intravenous iron is the optimal treatment option in this setting. The Preoperative intravenous (IV) iron to treat anaemia in major abdominal surgery (PREVENTT) phase III randomised controlled trial addresses this question of whether intravenous iron can effectively treat anaemia and improve patient outcomes in the surgical patient. ${ }^{5}$ One issue is that screening data have revealed the difficulties and a major issue of patients being referred for operations not having simple blood tests such as a full blood count or electrolytes. In the referral to treatment, 18-week pathway, this is often overlooked to meet timelines.

We ask for the general practice community to join us and contribute to this research with the end goal to improve patient outcome. Our emphasis placed on education and awareness of IDA, ensuring patients are identified, with the inclusion of up-to-date blood tests prior to referral to tertiary hospitals. Engagement with general practice with time to pre-optimise patients, diagnose the cause of anaemia, and develop a patient blood management plan would be a substantial contribution to the improved management of this condition.

Anna Butcher,

Division of Surgery and Interventional Science, University College London, London.

E-mail: a.butcherducl.ac.uk

Rebecca Swinson,

London School of Hygiene and Tropical Medicine, London.

Laura VanDyck,

London School of Hygiene and Tropical Medicine, London.

Tim Collier,

London School of Hygiene and Tropical Medicine, London.

Toby Richards,

Division of Surgery and Interventional Science, University College London, London.

\section{REFERENCES}

1. Keshav S, Stevens R. New concepts in iron deficiency anaemia. Br J Gen Pract 2017: DOI. https://doi.org/10.3399/bjgp17X688465. 
2. Kassebaum NJ, Jasrasaria R, Naghavi M, et al. A systematic analysis of global anemia burden from 1990 to 2010. Blood 2014; 123(5): 615-624.

3. Muñoz M, Gómez-Ramirez S, Kozek-Langeneker S. Pre-operative haematological assessment in patients scheduled for major surgery. Anaesthesia 2016; 71(Suppl 1): 19-28.

4. Fowler AJ, Ahmad T, Phull MK, et al. Metaanalysis of the association between preoperative anaemia and mortality after surgery. Br J Surg 2015: 102(11): 1314-1324.

5. Richards T, Clevenger B, Keidan J, et al. PREVENTT: preoperative intravenous iron to treat anaemia in major surgery: study protocol for randomised control trial. Trials 2015: 16: 254

DOI: https://doi.org/10.3399/bjgp17X690137

\section{Do primary care chaplains need training in mental health \\ issues?}

I read with interest $\mathrm{Dr}$ Macdonald's article, which showed that talking therapy by chaplains resulted in an equivalent improvement in patient wellbeing as antidepressants.

Leavey et $a l^{2}$ in an interview study concluded that clergy tend to explain mental health problems in terms of social factors with spiritual influences and for them the meaning of mental distress assumes more social and moral significance. Pennybaker et $a^{3}$ have suggested there is a need to provide chaplains with training in psychiatric illness and to more clearly define their role in mental health care.

Dr Macdonald suggests primary care chaplaincy could be considered as an alternative to cognitive behavioural therapy but before adopting this strategy more widely it would be useful to obtain the views of chaplains on what talking therapy means to them and what training they would need to provide it.

\section{lan J Hamilton,}

Researcher, Institute of Health and Wellbeing, University of Glasgow. E-mail: ijdhamiltondadoctors.org.uk

\section{REFERENCES}

1. Macdonald G. Primary care chaplaincy: a valid talking therapy? Br J Gen Pract 2017; https://doi. org/10.3399/bjgp17X689221.

2. Leavey G. Loewenthal K, King M. Locating the social origins of mental Illness: the explanatory models of mental illness among clergy from different ethnic and faith backgrounds. J Relig Health 2016; 55(5): 1607-1622

3. Pennybaker S, Hemming P. Roy D, et al. Risks, benefits and recommendations for pastoral care on inpatient psychiatric units: a systematic review. J Psych Pract 2016; 22(5): 363-381.

DOI: https://doi.org/10.3399/bjgp17X690149

\section{Incorporating cancer risk information into general practice: a qualitative study using focus groups with health professionals}

Usher-Smith et al report a useful study in the potential utility of cancer risk assessment tools in general practice. Readers may be interested to know that the www.qcancer.org tool, which calculates risk of a current but as yet undiagnosed cancer, was integrated into EMISWeb in 2016; the most popular GP computer system, used by over $55 \%$ of all GPs in the UK.

Also there is a new tool that predicts 10 -year risk of different types of cancer. taking account of family history and lifestyle as well as other risk factors that are readily available. ${ }^{2}$ There is an online calculator for women (http://qcancer.org/10yr/female/) and one for men (http://qcancer.org/10yr/male/).

\section{Julia Hippisley-Cox,}

Professor of Clinical Epidemiology and General Practice, University of Nottingham, and ClinRisk Ltd.

E-mail: julia.hippisley-coxßnottingham.ac.uk

\section{Competing interests}

Julia Hippisley-Cox is Professor of Clinical Epidemiology at the University of Nottingham and co-director of QResearch ${ }^{\circledast}$, a not-for-profit organisation that is a joint partnership between the University of Nottingham and Egton Medical Information Systems (leading commercial supplier of IT for $60 \%$ of general practices in the UK). Julia Hippisley-Cox is also a paid director of ClinRisk Ltd, which produces open- and closed-source software to ensure the reliable and updatable implementation of clinical risk algorithms within clinical computer systems to help improve patient care.

\section{REFERENCES}

1. Usher-Smith JA, Silarova B, Ward A, et al. Incorporating cancer risk information into general practice: a qualitative study using focus groups with health professionals. Br J Gen Pract 2017; DOI: https://doi.org/10.3399/bjgp17X689401.

2. Hippisley-Cox J, Coupland C. Development and validation of risk prediction algorithms to estimate future risk of common cancers in men and women: prospective cohort study. BMJ Open 2015; 5(3): e007825. DOI: 10.1136/bmjopen-2015-007825

DOI: https://doi.org/10.3399/bjgp17X690161

\section{The wrong paradigm may be driving drug glucose control in the face of the evidence}

Boussageon et al are the latest to highlight the apparent contradiction in our current thinking.

On the one hand, the epidemiological evidence shows a strong link between chronic hyperglycaemia (HbA1c) and adverse patient-important outcomes. On the other hand, the evidence from randomised controlled trial shows that lowering $\mathrm{HbA} 1 \mathrm{c}$ by drug treatment is ineffective or harmful to patient outcomes.

This contradiction is because we are using the wrong paradigm.

The current paradigm is that $\mathrm{HbA} 1 \mathrm{c}$ has a causal relationship with adverse outcomes and that lowering $\mathrm{HbA} 1 \mathrm{c}$ by any means must improve patient-important outcomes.

The alternative paradigm is that chronic hyperglycaemia is partly causal, but is only a late and easily measurable part of a more fundamental problem.

Our culturally 'normal' diet, based on carbohydrate, is biologically different from the diet the human species evolved to thrive on. A large proportion of people cannot tolerate a carbohydrate-based diet over years, even 'healthy whole grains'. Eating starch is eating glucose, which requires a corresponding insulin response. An insulin response with every snack and meal for years can, in genetically vulnerable people, cause insulin resistance with variable expression among people and among different body tissues. The Hyperinsulinaemia and Insulin Resistance (HAIR) is the underlying problem driving disorders of glucose and lipid metabolism, characterised by pathological fat deposition as central and visceral obesity, metabolic syndrome, and, when 